the respiratory movements; that it restored the consciousness from delirium, and that it produced free sweating; that its administration was not accompanied by any alarming symptoms; that there was no vomiting; that its effects did not last longer than six hours; that there was no lowering of the daily maximum temperature; and that there was no apprecia. ble effect upon the course of the disease proper.

To I)r. Kolipinski and the courteous gentlemen of the library of the Surgeon-General's Office, U. S. A., I return my sincere thanks for their valuable assistance in making a complete examination of the bibliography of this subject.

\section{ON THE IDENTITY OF YELLOW FEVER AND ACUTE MALARIA - CONSEQUENT CONTAGIOUSNESS OF MALARIA AND CURABILITY OF YELLOW FEVER. ${ }^{1}$}

BY VIELRA DE MELLO, M.D.,

MEMIBER OF THE ACADEMX OF MEDICINE OF RIO DE JANEIRO.

I.

Considering that pathologists and physicians of all countries are of one accord in admitting that "the epidemics of yellow fever are alway's preceded by serious cases of acute malaria," yellow. fever must needs then, in my opinion, express the state of saturation of the atmosphere by the swamp microbe, thus permitting to man a greater absorption in cue time, of the morbific principle; hence the very serious character of the symptoms presented;

Considering that the two morbid entities co-exist in the same zone and increase in direct ratio of the development of the malarious germ,-a fact largely observed at Rio de Janeiro, where yellow fever is a contemporary and a companion of the excavations, breaking out at the same time that these are effected, and following them in their way through the city;

Considering, besides, that yellow fever has no distinct characteristics of its own, - the symptoms that are ascribed to it being strictly the same that I have observed in serious cases of acute malaria, hamorrhage and black vomit included;

Considering likewise,-and this argument is of surpassing value,--that, morphologically, the element considered as the generator of yellow fever, as drawn by Dr. Domingos Freire, is strictly the same that I have met with in the blood, vomit and urine of $p a$ tients suffering from acute and chronic malaria, this last period of malaria serving exactly to avoid the objections of those who may ascribe to yellow fever a case of acute malaria, - a thing that cannot be even thought of in a chronic case;

Considering, moreover, that this very same element has been found by me in the water that is used for drinking by the inhabitants of places where malaria reigns endemically,--places where yellow fever is not even spoken of,-an argument that at once enlightens the etiology of malaria, and overthrows the objections of those who ascribe to pigmental alterations of the hæmatin the elements described by Laveran and confirmed by me;

\footnotetext{
${ }^{1}$ Communicated to the Académie de Sciences, of Paris, 1885
}

Considering, finally, that all the cases of malaria that could have been, and those that were classified as yellow fever, and were attended by me, yielded to the specific treatment of acute malaria,-unsuccess in those in which this treatment was employed being due, in my opinion, to insufficient doses, bad quality of the medicine used, or tardy interference, when the organism is no longer in a state to absorb it,-or because the disease is several days old; or, lastly, because the attack has been so violent as to cause the same profound disorders that in milder cases would take time to make their appearance;

I have come to the conclusion that yellow fezer is a graver modality of acute malaria, its superlative gravity; that, therefore, it is not an idiopathic morbid entity, as has been asserted until now, but the expression of gravity in another morbid state; and that the denomination of yellow fever should be substituted by the one of rrate malaria, this qualification serving to designate the highest intensity of malaria.

\section{II.}

Amongst the objections that can be made to these doctrines, objections that have already been presented to me, the one that seems most weighty is the following: "Yellow fever cannot be of the same nature as malaria, since the first is contagious and the second not."

This is a great mistake. In the first place, no one, to my knowledge, has been able to demonstrate the contagiousness of yellow fever; that is, the trans. missibility of the disease from body to body, by contact. In the second place, because malaria is susceptible of being transmitted by any individual to persons surrounding him, as well as of being transported to great distances, For example: An individual is possessed by the helococcus ( $\xi \lambda \rho 5$, swamp, marsh, and rónuns, in I atin coccus, coccum, a germ, a seed, a small round body. This denomination, created by myself to designate the microbe of malaria, is based on the rules established by Egger for the construction of neologisms). He retires to his room, where he remains for several days without appropriate medication. The helococcus not being now attacked, and finding in the organism of the patient a favorable field for its development, proceeds on its evolutionary march. 'The patient, whose emunctory apparatus works, discharges continually from his body a certain quantity of these microbes that are thrown into the surrounding air, where, if they meet with favorable conditions, they live, develop and procreate. 'Therefore, after a certain time, the rooms of this individual will be transformed into a genuine focus or nursery of helococci, and, consequently, whoever enters there may receive the same morbific element that is found in a marsh or swamp.

And here we have the explanatian of the contagiousness of "yellow fever," which is at the same time the explanation of the contagiousness of malaria; a question that has been despised, why I cannot tell, since it is a known fact, as no one dares to deny, that malaria is a microbiotic disease. Thus, a person who has been infected in a marsh, may, in turn, constitute another marsh, focus or nursery, as long as his 
organism affords to the helococcus the necessary conditions for its development and procreation.

And if such a case is likely to happen in reference to one single individual, it is much more likely to happen in places where the accumulation of patients is considerable; especially if the enteric form of malaria prevails, if hygienic rules are neglected, or if the facal matters are retained or thrown in the vicinity of these places.

Here is another example: A ship watering in a place infected by malaria, and carrying to its interior the helococcus, may, ipso facto, become a focus of malaria, and of the gravest kind; as its population not only breathes the air impregnated with the deleterious principle, but uses for drinking purposes the liquid drained from the very sources whence it emanates. Thence the greater gravity of cases of malaria occurring aboard ships, — cases diagnosticated as yellow fever,-a fact that has led certain physicians to admit, in opposition to all laws of pathology, a "ship yellow fever" and a "land yellow fever," the first being always of a much more serious character than the second.

Thus, malaria, though not a contagious disease in the strict sense of the word, is susceptible of being transported to great distances, and transmitted by man, under the condition that the helococcus in the vessel in which it is conveyed meets with the necessary conditions of life, development and procreation.

\section{IS TYPHOID FEVER EVER OF SPONTANEOUS ORIGIN?}

\author{
BY J. F. JENKINS, M.D., \\ OF TECUMSEH, MICH.
}

Whether typhoid fever is or is not of spontaneous origin, remains an unsettled question. taught that it is of spontaneous origin. man writers are of the opposite opinion. Murchison Many GerIn country practice we not unfrequently see cases like the following, with a distinct clinical history of typhoid fever:

H. P., family consisting of wife and four children, living in a rural district, where families are separated by distances of a quarter or half a mile. The eldest child, a girl aged i y years, was attacked with typhoid fever on October roth, I884, and was attended throughout her illness by Dr. North, of this place. The disease assumed a malignant form, and the patient died on the ninth day after taking her bed. Three weeks after her death the mother, aged 35, and a son, aged 7 years, were attacked with fever. During the first week of their illness they were under the care of a homœopathic physician, but the family becoming dissatisfied, the writer was called to attend them.

Both were typical cases of typhoid fever. The mother died on the twenty-eighth day; the boy made a slow recovery. 'The father, aged 35 years, and a son, aged 9 years, were taken down with the disease. Each was attended by a different physician, and both physicians diagnosticated typhoid fever and treated them accordingly.
Both father and son recovered. There were no cases of typhoid fever within a radius of five miles of this family, but the surroundings were bad. The water supply of the family was doubtless contaminated by human excreta. 'This appears to be the only reasonable cause which produced the attack of typhoid fever in this family.

There were no other cases in the neighborhood. Neither the nurses who cared for them during their illness nor the neighbors who attended at their burial were taken with the disease.

Similar examples have come under the writer's observation, where a family living almost completely isolated were taken with fever, whose clinical history proved beyond a doubt the nature of the disease, which in a large proportion of cases is readily diagnosticated from the so-called typho-malarial fever. The isolated cases so frequently met in country practice are strong proof that typhoid fever originates spontaneously, and that all that is required to produce it is the decomposition of facal and other organic matter, which usually contaminates the well from which drinking water is obtained.

Tecumseh, November 10, 1885 .

\section{MEDICAL PROGRESS.}

\section{MATERIA MEDICA AND THERAPEUTICS.}

The Antithermic Properties of Thaldin.Professor JACCOUD read a paper on this subject at the meeting of the Académie de Médecine, on October 27. His experiments were begun in February, r 885. Of the chemical history of this drug, it is only necessary to say that it belongs to the series of bases of chinoline, that its formula is $\mathrm{C}_{10} \mathrm{H}_{13} \mathrm{NO}$, that its scientific name is tetrahydro-parachinanisol, and that Skraup gave it the name thallin on account of its characteristic action in aquous solutions of thallium. The sulphate and tartrate of thallin occur in the form of crystalline white powders. 'The sulphate is soluble in five times its weight of cold water; the tartrate is a little less soluble. The urine of persons who have taken thallin has a brown tint, with a more or less pronounced greenish reflection. The addition of a few drops of perchloride of iron produces a red color, but there is nothing special in this reaction. But if the urine to which the perchloride has been added be treated with chloroform or ether, a characteristic green color is produced.

Jaccoud has used thallin in seventeen adult cases, including six cases of typhoid fever, seven cases of pulmonary tuberculosis with pseudo-continued fever, three cases of pneumonia, and one case of facial erysipelas. The sulphate and tartrate were used indifferently, and the effects are so similar that it is useless to try to make any distinction in a general study.

The minimum quantity given in a day was ro centig., the maximum daily dose I gramme. In the larger number of cases he gave from 40-50 centig. The mode of administration was always the same: the drug was given in unleavened bread, and whenever the daily dose was greater than I 5 centig., it 